\title{
Correction to: From Satellite Images to Field Survey: A Complete Scheme of Landslide InSAR Monitoring
}

Matteo Del Soldato, Lorenzo Solari, Davide Festa, Pierluigi Confuorto, Silvia Bianchini, and Nicola Casagli

\section{Correction to: \\ Chapter "From Satellite Images to Field Survey: A Complete Scheme of Landslide InSAR \\ Monitoring" in: F. Guzzetti et al. (eds.), Understanding and Reducing Landslide Disaster Risk, ICL Contribution to Landslide Disaster Risk Reduction, https://doi.org/10.1007/978-3-030-60227-7_47}

The book was inadvertently published with chapter author's incorrect family name. This information has been updated from "Del Soldato Matteo" to "Matteo Del Soldato" in the initially published version of chapter "From Satellite Images to Field Survey: A Complete Scheme of Landslide InSAR Monitoring". The correction chapter and the book have been updated.

The updated version of this chapter can be found at https://doi.org/10.1007/978-3-030-60227-7_47 